\title{
SLC5A5 Positive
}

National Cancer Institute

\section{Source}

National Cancer Institute. SLC5A5 Positive. NCI Thesaurus. Code C153265.

An indication that SLC5A5 expression has been detected in a sample. 